\title{
Validação das diretrizes gerais de comunicação do enfermeiro com o cego
}

\author{
Validation of the general guidelines of communication between the nurse and the blind \\ Validación de las directrices generales de la comunicación entre la enfermera y el ciego
}

\section{Lorita Marlena Freitag Pagliuca', Kátia Nêyla de Freitas Macêdo-Costa", Cristiana Brasil de Almeida Rebouças', Paulo César de Almeida"I, Antonia Ferreira Alves Sampaio"v \\ ' Universidade Federal do Ceará, Departamento de Enfermagem. Fortaleza-CE, Brasil. \\ "Universidade Federal da Paraíba, Centro de Ciências da Saúde. João Pessoa-PB, Brasil. \\ I' Universidade Estadual do Ceará, Centro de Ciências da Saúde, Departamento de Saúde Pública. Fortaleza-CE, Brasil.

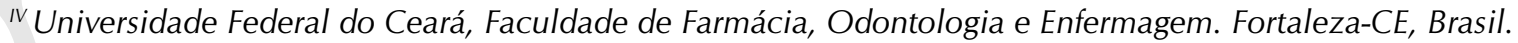

\author{
Submissão: 16-10-2013 Aprovação: 27-08-2014
}

\section{RESUMO}

Objetivou-se validar as diretrizes gerais da comunicação do enfermeiro com o cego. Estudo quantitativo, realizado entre abril de 2008 e março de 2009 em Fortaleza-CE. Participaram 30 enfermeiros e 30 cegos divididos em grupo controle e experimental. Realizaram-se 30 consultas de enfermagem filmadas e analisadas por especialistas. O grupo experimental apresentou desempenho bom e excelente em todas as diretrizes para a comunicação verbal e não verbal com o cego, contrariamente ao grupo controle. Os resultados do estudo apontam para a urgência da adoção do ensino destas diretrizes gerais de comunicação com cegos nos cursos de enfermagem, além de capacitar enfermeiros no cuidado a pessoas cegas.

Descritores: Enfermagem; Comunicação; Estudos de Validação; Pessoas com Deficiência Visual.

\section{ABSTRACT}

This quantitative study, conducted between 2008 April and 2009 March in Fortaleza-CE, Brazil, aimed to validate the general guidelines of the communication of the nurse with the blind. Thirty nurses and 30 blinds, divided into control and experimental groups, participated in the study. Thirty nursing consultations were videotaped and analyzed by experts. In contrast to the control group, the experimental group showed good and excellent performance in all guidelines for verbal and non-verbal communication with the blinds. The study results point to the urgency of adopting the teaching of these general guidelines for communicating with the blind in nursing courses, in addition to training nurses in caring for the blind people.

Key words: Nursing; Communication; Validation Studies; Visually Impaired Persons.

\section{RESUMEN}

Estudio cuantitativo, realizado entre abril de 2008 y marzo de 2009, en Fortaleza-CE, Brasil, que tuvo como objetivo validar los lineamientos generales de la comunicación del enfermero con los ciegos. Los participantes fueron 30 enfermeros y 30 ciegos, divididos en grupos control y experimental. Fueran realizadas 30 consultas de enfermería, registradas y analizadas por expertos. El grupo experimental mostró un buen y excelente rendimiento en todas las directrices para comunicación verbal y no verbal con los ciegos, en contraste con el grupo de control. Los resultados del estudio apuntan a la urgencia de la adopción de la enseñanza de estas directrices generales para la comunicación con los ciegos en los cursos de enfermería, además de la formación de enfermeras en el cuidado de las personas ciegas.

Palabras clave: Enfermería; Comunicación; Estudios de Validación; Personas con Daño Visual. 


\section{INTRODUÇÃO}

Deficiência é toda perda ou anormalidade de uma estrutura ou função psicológica, fisiológica ou anatômica que gera incapacidade para o desempenho de atividade dentro do padrão considerado normal para o ser humano. $\mathrm{O}$ termo deficiência visual refere-se a uma situação irreversível de diminuição da resposta visual, em virtude de causas congênitas ou hereditárias, mesmo após tratamento clínico e/ou cirúrgico e uso de óculos convencionais ${ }^{(1)}$.

A pessoa com deficiência visual, especialmente os cegos, encontra inúmeras dificuldades na integração social, na medida em que o despreparo e o desconhecimento da sociedade criam barreiras de toda natureza. Assim, obstáculos arquitetônicos nas vias e logradouros públicos, falta de sinalização sonora no trânsito, inexistência de materiais didáticos, problemas de comunicação, são alguns exemplos dos transtornos enfrentados no dia-a-dia por essas pessoas. A sociedade plural e, em particular, os profissionais de saúde, dentre eles os enfermeiros, precisam se conscientizar e entender que as pessoas, independentemente da sua condição, devem ser tratadas com igualdade, pois todas detêm os mesmos direitos fundamentais que provêm da humanidade e definem a dignidade da pessoa ${ }^{(2)}$. Embora o cego tenha limitações, isso não pode impedir sua comunicação e seu relacionamento com outras pessoas.

A comunicação é eficaz quando a mensagem transmitida torna-se comum. Esse processo pode ser afetado por vários fatores, dentre os quais se sobressaem: inadequação do emissor na maneira de se expressar; falta de habilidade do emissor para transmitir a mensagem e do receptor de compreendê-la; alterações da mensagem durante a transmissão em virtude de falha no canal de comunicação ${ }^{(3)}$.

O processo de comunicação é organizado tradicionalmente como comunicação verbal e não verbal, com referenciais teóricos específicos. A comunicação com a pessoa cega também obedece esta organização, mas tem características próprias. Antecedendo e acompanhando a comunicação com o cego sugerem-se diretrizes gerais que norteiam este processo. Nestas diretrizes, na comunicação verbal atenta-se para o uso da linguagem, o tom de voz e a manutenção da comunicação verbal; na comunicação não verbal, destacam-se o toque, a descrição do ambiente dentre outros componentes ${ }^{(4-5)}$.

Assim, precedendo este estudo foram elaboradas diretrizes gerais para a comunicação verbal e não verbal do enfermeiro com a pessoa cega. O objetivo deste estudo foi validar estas diretrizes durante a realização de consulta de enfermagem.

\section{METODOLOGIA}

Estudo de validação com abordagem quantitativa, realizado entre abril de 2008 e março de 2009, no Laboratório de Comunicação em Saúde do Departamento de Enfermagem da Universidade Federal do Ceará, ambiente preparado para experimentos de comunicação e com recursos para filmagem onde foi montado um consultório modelo.

Para melhor detalhamento, o conceito de validade é abordado como sendo o grau em que um instrumento mostra-se apropriado para mensurar o que supostamente ele deveria medir. Assim, quando se submete um instrumento ou material ao procedimento de validação, na realidade não é o instrumento ou material em si que está sendo validado, mas sim o propósito pelo qual está sendo usado(6).

Os sujeitos foram trinta enfermeiros que conduziram a consulta de enfermagem e que foram recrutados por convite afixado em três cursos de graduação em enfermagem na cidade de Fortaleza-CE; e pessoas cegas de ambos os olhos e seus acompanhantes convidados em uma associação de cegos do estado do Ceará. Como critério de inclusão, os enfermeiros deviam ser recém-formados e, portanto, com possível domínio de habilidades de comunicação para conduzir consulta de enfermagem. Os quinze primeiros compuseram o grupo controle e conduziram a consulta de enfermagem apoiados nos conhecimentos prévios e em um formulário padrão disponibilizado pela pesquisa.

Os outros quinze enfermeiros do grupo experimental foram preparados para utilização das diretrizes gerais para comunicação verbal e não verbal com o cego e tiveram aula expositiva sobre deficiência visual. Na primeira fase do treinamento foram abordadas diretrizes gerais de comunicação verbal com o cego que destacam que o enfermeiro deve dirigir-se ao cego quando fala com ele; empregar com naturalidade o termo cego; evitar palavras no diminutivo que infantilizam a relação; empregar palavras que indicam a direção em que o cego deve andar ou onde poderá encontrar um obstáculo (exemplos: em frente, à direita); falar com voz audível e clara, ou seja, não falar alto inferindo que o cego não houve; identificar-se, dizer seu nome e função, pois o cego não pode ler sua identificação; depois disto, solicite que ele se apresente, assim saberá como prefere ser chamado; a partir de então, chame-o pelo nome ou como preferiu ser chamado, isto faz com que o cego saiba que está falando com ele e não com outra pessoa presente no ambiente, por exemplo, seu acompanhante.

A segunda fase do treinamento contemplou a comunicação não verbal com o cego, sendo explicada a necessidade de manter-se atento e olhando para ele, isto para identificar sinais de expressão tais como de agrado ou não, de compreensão sobre o que está sendo falado; ao sentar-se ou permanecer de pé, posicionar-se em frente ao cego, desta forma ao falar, sua voz indicará sua posição e, se lateralizado, transmite a sensação de que você está atento a outro acontecimento; ao andar no ambiente mantenha a conversação, por exemplo, ao posicionar o cego na balança, ande na sua frente, pelo movimento do som ele saberá por onde andar; acomode o cego, dirija sua mão aos móveis que usará (exemplo, a cadeira, a maca); descreva o ambiente, seu tamanho aproximado, a localização das portas e janelas, a disposição dos móveis, informe a existência de outra pessoa no ambiente e lembre-se disto durante toda a consulta; toque ligeiramente a mão, braço ou ombro do cego durante a consulta, este gesto reforça a comunicação verbal e orientações transmitidas; evite gesticular, o cego não vê seus movimentos, ao pensar em mostrar uma cadeira, dê a informação verbal "a cadeira encontra-se a dois passos à sua direita".

Ainda no treinamento, os enfermeiros do grupo experimental simularam consultas em dupla: um com olhos vendados simulando ser cego e o outro como enfermeiro; logo após invertiam os papéis. Cada enfermeiro realizou três consultas simuladas, o 
que permitiu verificar que estavam aptos para iniciar a coleta de dados, e, propiciou reflexão sobre a experiência de não enxergar. Foram realizadas 30 consultas, destas, 15 do grupo controle e 15 do experimental. Não foi determinado tempo; portanto, o enfermeiro tinha autonomia para conduzir a consulta como achasse mais apropriado. Uma das pesquisadoras filmou as consultas com aquiescência dos participantes. Esta se manteve em outra sala, protegida por um vidro unidirecional que impedia que as pessoas em cena a visualizassem preservando a espontaneidade.

As filmagens foram analisadas por três juízes treinados que avaliaram se os enfermeiros que realizaram as consultas observaram ou não as diretrizes gerais da comunicação com o cego. No início da análise de cada filmagem, fazia-se revisão das diretrizes e do instrumento de análise. Assistia-se a filmagem completa para entendimento do contexto da consulta, em seguida, com interrupções a cada 30 segundos para registro no instrumento. Para evitar influência nas respostas, os juízes não foram informados sobre qual grupo estavam avaliando, se controle ou experimental, e, não havia troca de informações entre juízes. A análise individual e o preenchimento do instrumento eram realizados simultaneamente. As variáveis analisadas estão organizadas segundo as diretrizes da comunicação verbal e não verbal. O conteúdo estabelecido recebeu por parte dos especialistas a classificação péssimo/ruim, regular, bom e excelente.

Os dados foram processados no Statistical Package for Social Sciences (SPSS) 14.0 e analisados por meio de tabelas univariadas com frequência relativa e porcentagens. Para a associação entre as variáveis, empregaram-se os testes Qui-quadrado $\left(\chi^{2}\right)$, teste de Fisher-Freeman-Halton e máximo de verossimilhança. Fixou-se o nível de significância de $5 \%{ }^{(7)}$. Foi calculado também o índice de concordância entre os juízes (ICC) aceitando-se IC 95\%.

O estudo foi aprovado pelo Comitê de Ética em Pesquisa da UFC, sob o número 243/07. Os sujeitos do estudo assinaram o Termo de Consentimento Livre e Esclarecido. Para os sujeitos cegos o termo foi lido na presença de testemunha vidente que também assinou o documento.

\section{RESULTADOS}

A seguir será apresentada a validação das diretrizes gerais para a comunicação verbal do enfermeiro com o cego, a partir de comparações entre o grupo de enfermeiros controle e o experimental. (Tabela 1).

Tabela 1 - Comparação, entre grupo controle e experimental, das diretrizes gerais para a comunicação verbal do enfermeiro com o cego, Fortaleza-CE, 2009

\begin{tabular}{|c|c|c|c|c|c|c|c|c|c|}
\hline \multirow{2}{*}{ Diretrizes } & \multicolumn{2}{|c|}{ Péssimo/Ruim } & \multicolumn{2}{|c|}{ Regular } & \multicolumn{2}{|c|}{ Bom } & \multicolumn{2}{|c|}{ Excelente } & \multirow[t]{2}{*}{$\mathbf{P}$} \\
\hline & $\mathbf{N}$ & $\%$ & $\mathbf{N}$ & $\%$ & $\mathbf{N}$ & $\%$ & $\mathbf{N}$ & $\%$ & \\
\hline \multicolumn{10}{|l|}{ 1. Dirige-se ao cego } \\
\hline Controle & 3 & 6,7 & 8 & 17,8 & 28 & 62,2 & 6 & 13,3 & $0,0001^{2}$ \\
\hline Experimental & - & - & & & 4 & 8,9 & 41 & 91,1 & \\
\hline \multicolumn{10}{|c|}{ 2. Emprega termo cego } \\
\hline Controle & - & - & 16 & 35,6 & 21 & 46,7 & 8 & 17,8 & 0,0001 \\
\hline Experimental & - & - & & & 11 & 24,4 & 34 & 75,6 & \\
\hline \multicolumn{10}{|c|}{ 3. Evita palavras no diminutivo } \\
\hline Controle & - & - & 8 & 17,8 & 22 & 48,9 & 15 & 33,3 & $0,0001^{1}$ \\
\hline Experimental & - & - & 1 & 2,2 & 12 & 26,7 & 32 & 71,1 & \\
\hline \multicolumn{10}{|c|}{$\begin{array}{l}\text { 4. Emprega palavras que indicam } \\
\text { a direção }\end{array}$} \\
\hline Controle & 44 & 97,8 & 1 & 2,2 & - & - & - & - & $0,0001^{2}$ \\
\hline Experimental & - & - & & & 10 & 22,2 & 27 & 60,0 & \\
\hline \multicolumn{10}{|c|}{ 5. Fala com voz audível/clara } \\
\hline Controle & 2 & 4,4 & 17 & 37,8 & 22 & 48,9 & 4 & 8,9 & $0,0001^{2}$ \\
\hline Experimental & - & - & & & 15 & 33,3 & 27 & 60,0 & \\
\hline \multicolumn{10}{|l|}{ 6. Identifica-se } \\
\hline Controle & 19 & 42,2 & 4 & 8,9 & 13 & 28,9 & 9 & 20 & 0,0001 \\
\hline Experimental & - & - & 2 & 4,4 & 7 & 15,6 & 36 & 80 & \\
\hline \multicolumn{10}{|c|}{ 7. Solicita apresentação } \\
\hline Controle & 43 & 95,6 & - & - & 2 & 4,4 & - & - & 0,0001 \\
\hline Experimental & - & - & - & - & 6 & 13,3 & 39 & 86,7 & \\
\hline \multicolumn{10}{|c|}{ 8. Chama pelo nome ou apelido } \\
\hline Controle & 10 & 22,2 & 10 & 22,2 & 18 & 40 & 7 & 15,6 & 0,0001 \\
\hline Experimental & - & - & 3 & 6,7 & 20 & 44,4 & 22 & 48,9 & \\
\hline
\end{tabular}


Tabela 2 - Comparação, entre grupo controle e experimental, das diretrizes gerais para a comunicação não verbal do enfermeiro com o cego, Fortaleza-CE, 2009

\begin{tabular}{|c|c|c|c|c|c|c|c|c|c|}
\hline \multirow{2}{*}{ Diretrizes } & \multicolumn{2}{|c|}{ Péssimo/Ruim } & \multicolumn{2}{|c|}{ Regular } & \multicolumn{2}{|c|}{ Bom } & \multicolumn{2}{|c|}{ Excelente } & \multirow[t]{2}{*}{$\mathbf{P}$} \\
\hline & $\mathbf{n}$ & $\%$ & $\mathbf{N}$ & $\%$ & $\mathbf{n}$ & $\%$ & $\mathbf{N}$ & $\%$ & \\
\hline \multicolumn{10}{|c|}{$\begin{array}{l}\text { 1. Mantém-se atento olhando para } \\
\text { o cego }\end{array}$} \\
\hline Controle & 12 & 26,7 & 13 & 28,9 & 14 & 31,1 & 6 & 13,3 & $0,0001^{1}$ \\
\hline Experimental & - & - & - & - & 4 & 8,9 & 41 & 91,1 & \\
\hline \multicolumn{10}{|c|}{ 2. Posiciona-se em frente ao cego } \\
\hline Controle & 8 & 17 & 15 & 33,3 & 16 & 35,6 & 6 & 13,3 & $0,0001^{1}$ \\
\hline Experimental & 1 & 2,2 & - & - & 7 & 15,6 & 37 & 82,2 & \\
\hline \multicolumn{10}{|c|}{$\begin{array}{l}\text { 3. Comunica-se andando na frente } \\
\text { do paciente }\end{array}$} \\
\hline Controle & 45 & 100 & - & - & - & - & - & - & $0,0001^{2}$ \\
\hline Experimental & 1 & 2,2 & 2 & 4,4 & 7 & 15,6 & 35 & 77,8 & \\
\hline \multicolumn{10}{|l|}{ 4. Acomoda o cego } \\
\hline Controle & 39 & 86,7 & 5 & 11,1 & 1 & 2,2 & - & - & $0,0001^{2}$ \\
\hline Experimental & - & - & - & - & 7 & 15,6 & 38 & 84,4 & \\
\hline \multicolumn{10}{|l|}{ 5. Descreve ambiente } \\
\hline Controle & 45 & 100 & - & - & - & - & - & - & $0,0001^{1}$ \\
\hline Experimental & - & - & - & - & 8 & 17,8 & 37 & 82,2 & \\
\hline \multicolumn{10}{|c|}{ 6. Informa existência de outra pessoa } \\
\hline Controle & 45 & 100 & - & - & - & - & - & - & $0,0001^{2}$ \\
\hline Experimental & - & - & 1 & 2,2 & 10 & 22,2 & 34 & 75,6 & \\
\hline \multicolumn{10}{|c|}{$\begin{array}{l}\text { 7. Toca ligeiramente a mão, braço } \\
\text { ou ombro }\end{array}$} \\
\hline Controle & 43 & 95,6 & 1 & 2,2 & 1 & 2,2 & - & - & $0,0001^{1}$ \\
\hline Experimental & - & - & 6 & 13,3 & 12 & 26,7 & 27 & 60,0 & \\
\hline \multicolumn{10}{|l|}{ 8. Evita gesticular } \\
\hline Controle & 31 & 68,9 & 13 & 28,9 & 1 & 2,2 & - & - & $0,0001^{2}$ \\
\hline Experimental & - & - & & & 5 & 11,1 & 40 & 88,9 & \\
\hline
\end{tabular}

(1)Teste de $x^{2}$

(2) Teste de Fisher-Freeman-Halton.

ICC =0,944; IC95\%: [0,915-0,960].

As diretrizes gerais para a comunicação verbal consideradas péssimas ou ruins estiveram ausentes nos oito itens avaliados no grupo experimental. Em todas as diretrizes o grupo experimental apresentou melhor desempenho do que o controle $(p<0,05)$. O índice de concordância (ICC) entre os juízes foi significante $(0,992-0,994)$. A seguir a Tabela 2 mostrará as comparações das diretrizes dos dois grupos de acordo com a comunicação não verbal com o paciente.

Nas diretrizes gerais da comunicação não verbal com o cego o grupo experimental com enfermeiros treinados obteve predominantemente desempenho bom/excelente. Porém, um enfermeiro não se posicionou em frente ao cego, quatro não associaram o cumprimento verbal a aperto de mão e um, falava andando a frente do cego. Aqui, também o índice de concordância (ICC) entre os juízes foi significante [0,915 - 0,960].

\section{DISCUSSÃO}

As diretrizes da comunicação verbal compreendem a oralização e a escrita. O enfermeiro e o cego deste estudo têm o português como língua pátria. A escrita do ser humano que enxerga é em tinta e a do cego em braile. Escrita em tinta para o cego é uma folha em branco e, raramente o enfermeiro escreve em braile.

Ao estabelecer a comunicação verbal recomenda-se dirigir-se ao cego, ou seja, falar com ele, porém, frequentemente este comparece com acompanhante, fazendo com que seja ignorado durante a consulta, prevalecendo o diálogo com o acompanhante. Ao efetuar uma consulta ou qualquer interação profissional, o paciente deve ser estimulado a participar ativamente para aproveitar ao máximo seu potencial no processo saúde-doença ${ }^{(4)}$. Isso não deve ser diferente com as pessoas cegas, já que as mesmas precisam expor suas particularidades necessitando muitas vezes de privacidade, o que torna evidente a importância da habilidade do enfermeiro de se comunicar com essas pessoas, sem a presença de um acompanhante ${ }^{(8)}$. Neste estudo ambos os grupos obtiveram avaliação entre bom e excelente com um total de $75 \%$ no grupo controle e $100 \%$ no experimental, havendo diferença estatística significativa.

A expressão "cego" designa pessoa com deficiência específica, e vai ao encontro da evolução histórica do termo ${ }^{(9)}$. Novamente, o grupo experimental obteve desempenho entre bom e excelente (100\%). A expressão "cego" ainda é interpretada como pejorativa em determinados contextos sociais. Os cegos aceitam esta denominação com naturalidade, aderindo ao conceito de 
pessoa com deficiência. Fazer com que o profissional aceite este conceito evidencia compreensão da proposta deste estudo.

Há uma tendência na linguagem oral do uso do diminutivo, que tanto pode denotar carinho ou ser interpretado como não reconhecimento da autonomia. De acordo com a experiência e contato das pesquisadoras com este público, percebeu-se que as pessoas cegas se desagradam deste tratamento. A sociedade, em algumas situações, utiliza expressões diminutivas que caracterizam pessoa dependente, que merece comiseração. Não houve neste estudo este tipo de tratamento por parte dos profissionais, reforçando a formação adequada do enfermeiro para o respeito de cidadania. Este resultado foi melhor no grupo experimental com $87,8 \%$ entre bom e excelente.

Ao entrar em ambiente desconhecido, a pessoa cega deve receber descrição quanto a tamanho, distribuição de portas e janelas e do mobiliário. É importante orientá-la usando expressões do tipo à direita ou esquerda, a tantos passos, no sentido dos ponteiros do relógio dentre outras que indiquem direção e volume no interior do ambiente. Desse modo, indica-se para onde deve andar e a quantos passos aproximadamente encontrará, por exemplo, uma cadeira para sentar-se. Os enfermeiros do grupo controle tiveram desempenho péssimo/ ruim $(97,8 \%)$ das situações, ou seja, não orientaram o cego no ambiente do consultório. O grupo experimental obteve resultado entre bom e excelente $(82,2 \%)$ confirmando o aprendizado sobre diretrizes gerais para comunicação com o cego.

A fala deve respeitar uma pronúncia clara, evitando expressões corriqueiras e também aquelas de origem técnica que podem não fazer parte do vocabulário do receptor da mensagem. Ao estabelecer o diálogo o profissional da saúde deve manter posição frontal ao cego e observar sinais não verbais quanto à adequação do volume da voz e expressões ou movimentos que indiquem compreensão ou não do conteúdo ${ }^{(10)}$. Neste quesito, o grupo controle obteve desempenho péssimo/ ruim e regular $(42,2 \%)$ enquanto o grupo experimental registrou de bom a excelente $(93,3 \%)$. Recomenda-se atenção para manter tom de voz normal, há uma tendência de o vidente falar mais alto quando se dirige ao cego, e este declara em parte sério e também brincando: "sou cego não surdo".

Identificar-se ao interlocutor deve ser uma ação desempenhada por todo profissional de saúde ${ }^{(4)}$, mas frente ao cego isto se torna primordial, pois a informação contida no crachá de identificação profissional lhe é inacessível. Sendo assim o enfermeiro deve informar sua atividade e seu nome, o que considerado de forma boa e excelente no grupo controle $(48,9 \%)$ e no experimental $(95,6 \%)$. Portanto, significativamente melhor no grupo que recebeu treinamento.

Da mesma forma como se apresenta, o enfermeiro deve solicitar ao cego sua apresentação. Denota reconhecimento à sua individualidade. Neste quesito, o grupo controle registrou desempenho péssimo/ruim em 95,6\% das interações; o grupo experimental teve avaliações boas e excelente $(100 \%)$.

Durante o transcorrer da consulta o enfermeiro deve dirigir-se ao paciente chamando-o pelo nome ou, apelido se assim ele preferir $r^{(5)}$. Neste estudo o grupo controle teve desempenho entre péssimo/ruim e regular (44,4\%). No grupo experimental estes valores foram bons e excelentes $(88,9 \%)$. Há de se convir que esta forma de tratamento não deve ser exclusiva para a pessoa cega, mas geral a todos os pacientes o que torna este resultado mais crítico.

A comunicação não verbal compreende a expressão facial, os movimentos do corpo, a aproximação ou distanciamento entre os interlocutores. Sendo assim, gestos, postura, pausa são indicadores de comunicação não verbal(11-12). O ambiente também favorece ou prejudica a comunicação de acordo com sua organização de mobiliário, interrupções, privacidade, movimentos externos e ruídos $^{(5)}$. Manter-se atento durante o diálogo e olhando para o interlocutor permite que o enfermeiro observe a expressão facial, movimentos do corpo e das mãos que são indicadores da sua compreensão do que está sendo dito. Estudo evidenciou que foi possível identificar as expressões faciais do cego quando este estiver utilizando o computador ${ }^{(13)}$. Da mesma forma, o enfermeiro deve estar atento às expressões faciais durante a consulta. Como o cego não observa esta gestualidade sua expressão facial é pobre e pouco elucidativa, exigindo maior atenção do enfermeiro ${ }^{(1415)}$. Por outro lado ele consegue perceber a concentração ou não do enfermeiro pela entonação e direção da voz. Na avaliação dos especialistas, os enfermeiros do grupo controle tiveram desempenho péssimo/ruim e regular $(55,6 \%)$ e o experimental bom e excelente $(100 \%)$. Atribui-se este resultado ao treinamento disponibilizado ao grupo experimental. Conforme experiência das autoras é relevante atentar para esses aspectos, pois do ponto de vista de quem não tem a visão comprometida torna-se bastante complexo.

Ao estabelecer o diálogo o enfermeiro deve posicionar-se em frente ao paciente, isto reforça a ideia de atenção e facilita a comunicação ${ }^{(5)}$. Sentar-se lateralmente dificulta a percepção das expressões não verbais, esta posição foi adotada por $50 \%$ dos enfermeiros do grupo controle enquanto que do grupo experimental 97,8\% posicionou-se em frente ao cego.

Ao recepcionar o cego na entrada do ambiente de consulta o enfermeiro deve andar à frente do cego, oferecer-lhe o braço e comunicar-se verbalmente. Desta forma, o conduzido é dirigido pelos movimentos do enfermeiro e direção da voz. Os enfermeiros do grupo controle, por ignorarem esta diretriz de comunicação com o cego, não a obedeceram (100\%).

Para acomodar o paciente o enfermeiro o conduz e oferece a cadeira fazendo com que toque no espaldar, este gesto é suficiente para que saiba como se sentar. Esta diretriz foi ignorada pelo grupo controle $(99 \%)$ e realizada pelo grupo experimental. Há de se considerar que em ambiente desconhecido do cego o mesmo deverá ser descrito oralmente, dando ideia aproximada das dimensões do aposento em termos de metros ou passos e, localizar neste espaço os móveis e equipamentos existentes, novamente o grupo experimental teve desempenho bom e excelente $(100 \%)$ neste item.

Sabe-se que um indivíduo com deficiência, seja ela adquirida ou não, necessita aprender e/ou aprimorar, por meio de reabilitação, suas atividades de vida, minimizando a possibilidade de acidentes e dependência. Institutos, associações e organizações têm, comumente, oferecidos essas ações. Contudo, ainda não existe esta preocupação por parte de outros setores da sociedade que são potencialmente passíveis de conviver com essas pessoas, mesmo reconhecendo que treinamentos externos podem ser solicitados ${ }^{(16)}$. Nossa experiência tem mostrado que 
profissionais de saúde, em especial de enfermagem, desconhecem e não são preparados para guiar, caminhar e estabelecer uma comunicação terapêutica com pessoas cegas.

Eventualmente pode estar presente uma terceira pessoa e, possivelmente, o cego poderá não se aperceber disto; portanto, cabe ao enfermeiro informar esta presença bem como quando de sua saída do recinto. Nas consultas do grupo controle isto não foi feito $(100 \%)$, no grupo experimental o desempenho foi bom e excelente $(97 \%)$. Este cuidado fará com que o cego perceba sua privacidade respeitada, poderá então interromper uma informação confidencial e reforçará a confiança em seu interlocutor. Se o enfermeiro necessitar se ausentar do ambiente deverá comunicar sua saída e posterior retorno. Pesquisa evidenciou que o cego tem a expectativa de conhecer a identidade, as expressões faciais e gestuais e, a aparência física das pessoas com quem interagem ${ }^{(17)}$.

Recomenda-se durante a consulta que o enfermeiro regularmente toque ou aperte a mão, o braço ou ombro do cego, este gesto tem a característica de reforçar a comunicação verbal e também estabelecer a afetividade e, denota atenção. $\mathrm{O}$ toque fortalece as orientações transmitidas na consulta. Esta gestualidade demostra afetividade, substitui um sorriso ou movimento de cabeça e reforça um conteúdo transmitido oralmente, valoriza a ideia de compreensão da mensagem. O grupo controle teve desempenho péssimo/ruim $(97,8 \%)$ enquanto que o experimental alcançou resultado de excelência $(86,7 \%)$.

Nesta mesma linha de raciocínio, a gesticulação do enfermeiro apontando objetos ou locais é incompreensível para o cego. Exemplos desta gesticulação foram observados durante as filmagens, quando o enfermeiro aponta e solicita ao cego "Vá até a balança", ou então "Use a escada para subir na maca de exame" sendo que estas citações não foram acompanhadas de descrição da distância ou da condução do cego oferecendo o braço. O desempenho do grupo controle foi péssimo/ruim em $68 \%$ das avaliações e bom/excelente para o grupo experimental (100\%).

Observa-se claramente em todas as situações de gesticulação e outras formas culturais de se comunicar, como acenos, apertos de mão, entre outros, que os profissionais que não foram treinados sobre as diretrizes gerais não conseguiram ter um bom desempenho com os cegos. Não foi objetivo desse estudo, porém pode-se indagar, se essas interações poderiam até influenciar na validação das mensagens, no prognóstico e na adesão às intervenções de enfermagem, observando-se ainda se existe diferença referente a esses aspectos entre $\mathrm{o}$ grupo atendido por enfermeiros experimental e o controle.

A comunicação pode se tornar efetivamente terapêutica se durante a interação entre pacientes cegos e profissionais de saúde houver maior cuidado ao usar a comunicação verbal e não verbal, com treinamentos específicos, adequação física das unidades que recebem essa clientela bem como, de preparação nas universidades que formam esses profissionais pelo menos sobre as diretrizes gerais de comunicação com esses sujeitos.

\section{CONSIDERAÇÕES FINAIS}

A comunicação verbal e não verbal com o cego obedeceu diretrizes gerais que são específicas para estas pessoas. Dentre as diretrizes da comunicação verbal destacam-se dirigir-se ao cego durante consulta de enfermagem, empregar com naturalidade o termo cego, evitar palavras no diminutivo, empregar palavras que indiquem direção dentro de um determinado ambiente, falar com voz clara e audível, identificar-se ao cego dizendo nome e função, pedir que o cego se apresente e chamá-lo pelo nome.

Para a comunicação não verbal as diretrizes enfatizam que o enfermeiro deve manter-se atento ao diálogo, posicionar-se em frente ao cego, andar à sua frente e comunicar-se simultaneamente, acomodá-lo no ambiente e descrever o mesmo, informar a presença de outras pessoas no ambiente, tocar na mão braço ou ombro como gesto de reforço e afetividade, evitar gesticular ou apontar móveis ou objetos imaginando que o cego poderá compreendê-lo.

Assim, fica evidente que há especificidades de comunicação verbal e não verbal com o cego que não são exigidas para a comunicação com quem tem a visão preservada. Pode-se questionar e aceitar como limitação do estudo a ausência de avaliação dos conhecimentos sobre comunicação verbal e não verbal do enfermeiro com pessoas videntes; este conhecimento de base é que deveria subsidiar o encaminhamento da consulta pelos enfermeiros do grupo controle.

As diretrizes da comunicação verbal e não verbal com o cego foram transmitidas para o grupo de enfermeiros do grupo experimental. O grupo controle conduziu a consulta desconhecendo estas diretrizes, utilizando seus conhecimentos tradicionais sobre comunicação. Na avaliação dos grupos, o controle obteve resultados péssimo/ruim em todas as diretrizes enquanto que o grupo experimental obteve resultado bom/excelente em todos. A estatística aplicada neste estudo confirmou a significância dos resultados e a qualidade do treinamento oferecido ao grupo experimental.

Os resultados apontam para a urgência da adoção do ensino destas diretrizes gerais de comunicação com cegos nos cursos de enfermagem e treinamento com enfermeiros para qualificar o cuidado ao cego. Pode-se mencionar como limitações a amostra ser composta por enfermeiros de uma única região do país, o que aponta para a perspectiva de experimentos similares em outros locais.

\section{REFERÊNCIAS}

1. Organização Mundial da Saúde. Classificação internacional de funcionalidade, incapacidade e saúde. São Paulo (SP): EDUSP; 2005.

2. França ISX, Pagliuca LMF. Acessibilidade das pessoas com deficiência ao SUS: fragmentos históricos e desafios atuais. Rev RENE [Internet]. 2008 [acesso em 21 de julho de 2013];9(2):129-37. Disponível em: http:// www.revistarene.ufc.br/revista/index.php/revista/ article/view/572 
3. Braga EM, Silva MJP. Comunicação competente: visão de enfermeiros especialistas em comunicação. Acta Paul Enferm [Internet]. 2007 [acesso em 21 de julho de 2013];20(4):4104. Disponível em: http://www.scielo.br/scielo.php?script= sci_arttext\&pid = S0103-21002007000400004

4. Costa KNFM, Pagliuca LMF, Almeida PC, Cardoso MVL$M L$, Rebouças CBA. Aspects of verbal communication between nurses and the visually impaired. Rev RENE. 2009; 10(2):29-36.

5. Rebouças CBA, Pagliuca LMF, Sawada NO, Almeida PC. Validation of a non-verbal communication protocol for nursing consultations with blind people. Rev RENE. 2012;13(1):125-39.

6. Polit DF, Beck CT, Hungler BP. Análise quantitativa. In: Polit DF, Beck CT, Hungler BP. Fundamentos de pesquisa em enfermagem: métodos, avaliação e utilização. Porto Alegre (RS): Artmed; 2011. p.167-98.

7. Gorenstein C, Andrade LHSG, Zuardi AW. Escalas de avaliação clínica em psiquiatria e psicofarmacologia. São Paulo (SP): Lemos Editorial; 2000.

8. França ISX, Pagliuca LMF, Baptista RS. Policies for the inclusion of disabled people: limits and possibilities. Acta Paul Enferm [Internet]. 2008 [acesso em 21 de julho de 2013];21(1):112-6. Disponível em: http://www.scielo.br/ pdf/ape/v21n1/17.pdf

9. Baptista RS, Pagliuca LMF. Disabled person an evolutionary perspective: conceptual analysis. Online Braz J Nurs. [Internet] 2009 [cited 2013 July 21];8(3). Available from: http://www.objnursing.uff.br/index.php/nursing/article/ view/j.1676-4285.2009.2511/551

10. Pagliuca LMF, Uchoa RS, Machado MM. Blind parents: their experience in care for their children. Rev Latinoam Enferm [Internet]. 2009 [cited 2013 July 21];17(2):2714. Available from: http://www.scielo.br/scielo.php?pid= S0104-11692009000200021\&script=sci_arttext

11. Frankel RM, Flanagan $M$, Ebright $P$, Bergman $A, O^{\prime}$ Brien $\mathrm{CM}$, Franks $\mathrm{Z}$, et al. Context, culture and (non-verbal) communication affect handover quality. BM] Qual Saf [Internet]. 2012 [cited 2013 July 21];21(Suppl. 1):121-7. Available from: http://www.ncbi.nlm.nih.gov/pubmed/23173182

12. Paiva SS, Galvão MTG, Pagliuca LMF, Almeida PC. Non-verbal mother-child communication in conditions of maternal HIV in an experimental environment. Rev Latinoam Enferm [Internet]. 2010 [cited 2013 July 21];18(1):41-7. Available from: http://www.ncbi.nlm.nih. gov/pubmed/20428695

13. Astler D, Chau H, Hsu K, Hua A, Kannan A, Lei L, et al. Increased accessibility to nonverbal communication through facial and expression recognition technologies for blind/visually impaired subjects. ACM [Internet]. 2011 [cited 2013 July 21];11:259-60. Available from: http://delivery.acm. org/10.1145/2050000/2049596/p259-astler.pdf

14. Kunz M, Faltermeier N, Lautenbacher S. Impact of visual learning on facial expressions of physical distress: a study on voluntary and evoked expressions of pain in congenitally blind and sighted individuals. Biol Psychol [Internet]. 2012 [cited 2013 July 21];89(2):467-76. Available from: http://www.ncbi.nlm.nih.gov/pubmed/22227356

15. Pagliuca LMF, Barbosa GOL, Wanderley LD, Oliveira PMP. Analysis of the verbal and non-verbal communication of a blind mother with motor impairment during breastfeeding. Rev Bras Enferm. 2011; 64(3):431-7.

16. Franca ISX, Pagliuca LMF, Baptista RS, França EG, Coura AS, Souza JA. Violência simbólica no acesso das pessoas com deficiência às unidades básicas de saúde. Rev Bras Enferm. 2010;63(6):964-70.

17. Krishna S, Colbry D, Black J, Balasubramanian V, Panchanathan $\mathrm{S}$. A systematic requirements analysis and development of an assistive device to enhance the social interaction of people who are blind or visually impaired. In: "Workshop on Computer Vision Applications for the Visually Impaired. Marseille: France; [Internet] 2008 [cited 2013 July 21]. Available from: http://www.ski.org/Rehab/Coughlan_lab/General/CVAVI08.html 